\title{
ICYMI: Canadian health news roundup
}

- Instead of relying on home-grow ops and small-scale producers to feed Canada's supply of medical marijuana, the federal government is turning to private companies that run large marijuana farms, which could eventually create a \$1.3-billion free market supported by an expected 450000 users of medical cannabis.

- For $40 \%$ of Canadians, a serious health problem leads to financial hardship, and only $13 \%$ of Canadians set aside money for health costs not covered by insurance, forcing many to turn to credit cards, lines of credit or personal savings.

- Canada ranks 5th of 91 countries in terms of the well-being of its older population based on factors including income and health, a few notches below top-ranked Sweden but well above last-place Afghanistan.

- There were 901 reports of selfinjury involving 264 inmates (male and female) in Canadian federal correctional facilities in 2012-13, a three-fold increase over five years, with Aboriginal inmates accounting for $35 \%$ of incidents and more than a third involving the same 37 female inmates.

- Health Minister Rona Ambrose announced that the government is removing heroin from a special access program that allows Canadians access to illicit drugs under certain circumstances, but the ban will not affect academic research or clinical trials.

- About half of Canadian veterans with incapacitating injuries that prevent them from obtaining gainful employment face lives of poverty because they don't receive the financial benefits intended for those who are "severely and permanently impaired."

- In Prince Edward Island, a new catastrophic drug plan has come into effect, capping out-of-pocket expenses for pharmaceuticals based on household income, and leaving New Brunswick as the only remaining province without such a plan.
- The IWK Health Centre in Halifax, Nova Scotia, is reporting an increase in babies with plagiocephaly, a condition characterized by flat or misshapen areas on the head that is primarily caused by spending too much time in the same position, such as in a car seat or bouncy chair.

- Hospitals and health care centres across Quebec want to opt out of the provincial government's proposed prohibition on the wearing of religious symbols, fearing the ban will introduce tensions and drive away researchers and other medical professionals.

- The federal government has handed control over health care for Aboriginal people in British Columbia to a new entity called the First Nations Health Authority. The government will transfer $\$ 4.7$ billion to the new authority over a decade, with the province kicking in an additional $\$ 83.5$ million over nine years. Roger Collier, CMAJ

CMAJ 2013. DOI:10.1503/cmaj.109-4624 